\title{
Evolution of pore structure in blended systems
}

\author{
E. Berodier *, K. Scrivener \\ Laboratory of Construction Materials, Ecole Polytechnique Fédérale de Lausanne, Lausanne Switzerland
}

\section{A R T I C L E I N F O}

\section{Article history:}

Received 28 August 2014

Accepted 24 February 2015

Available online 13 March 2015

\section{Keywords:}

Pore structure

Microstructure

Cement hydration

Blast furnace slag

Fly ash

\begin{abstract}
A B S T R A C T
In this study, the effect of SCM in the cement paste was isolated by using ternary systems combining Portland cement, quartz and SCM. The results show clear differences in how the hydrates from the reaction of clinker, slag and fly ash fill space. The reaction of slag is more efficient than that of fly ash in modifying the porosity. Our results indicate that Portland cement (PC), slag and fly ash reactions are limited at later ages by the lack of water-filled capillary pores. The higher the space available, with increasing the water/solids ratio, the later the reaction is limited. This explains the lower degree of reaction of SCM in blended systems at high replacement levels.
\end{abstract}

(c) 2015 Elsevier Ltd. All rights reserved.

\section{Introduction}

The mechanical and physical behavior of a material strongly depends on its microstructure. Blended cement systems are widely used today owing to their good performance compared to plain Portland cement and lower environmental impact. However the mechanisms of the microstructure development and thus the achievement of properties are not well understood. The main problem is to isolate the contribution of the SCM to the microstructural development of blended systems as the reaction of the SCM occurs simultaneously with the hydration of the clinker component.

SCMs are widely reported to change the phase assemblage and the composition of $\mathrm{C}-\mathrm{S}-\mathrm{H}$ in blended cements [1,2]. The major changes are related to the $\mathrm{C}-\mathrm{S}-\mathrm{H}$ composition which tends to have lower $\mathrm{Ca} / \mathrm{Si}$ and higher $\mathrm{Al} / \mathrm{Si}$ ratios than in PC paste [3]. These modifications in the $\mathrm{C}-\mathrm{S}-\mathrm{H}$ composition have been associated with a change in morphology of $\mathrm{C}-\mathrm{S}-\mathrm{H}$. At high replacement of slag or fly ash, the morphology of C-S-H was changed from fibrillar to foil-like morphology [4,5]. It is not clear how such changes in morphology or, more importantly, how the distribution of hydrates from the reaction of SCM changes the overall porosity. Earlier studies used MIP with severe drying conditions [6-8] that induced major changes in the pore structure.

Few techniques give information on the pore structure development. One of the most commonly used techniques to characterize the pore structure of cementitious materials is mercury intrusion porosimetry. This technique is based on the intrusion of a non-wetting fluid (mercury) into the pore structure under increasing pressure. The

* Corresponding author at: EPFL STI IMX LMC, Station 12, 1015 Lausanne. Tel.: + 4121 69 36781; fax: + 41216933752

E-mail address: elise.berodier@epfl.ch (E. Berodier).
Washburn equation is used to relate the pressure to pore "size". The interpretation of the MIP curves has been fervently discussed due to limitations of the technique and assumptions required $[9,10]$. The most important of these is that MIP actually measures the pore entry sizes rather than real pore sizes. This effect is more significant than might be expected, as often a high volume of pores only becomes accessible below a certain pore entry diameter, even though much of this porosity would have a higher pore "size" according to other interpretations. This effect is often called "ink-bottle effect", but this terminology can be misleading as it gives an image of only dead end pores rather than large interconnected volumes accessible at a given entry size. However, from some perspectives, this phenomenon may be an advantage as it gives an indication of the entry size of the connected porosity.

Another controversial issue is the effect of drying. In the past many studies used samples oven dried at $105^{\circ} \mathrm{C}$. Oven drying causes a lot of damage and leads to high pore entry sizes. Solvent exchange followed by vacuum drying seems to be the best method to stop the hydration [9,11-13] although isopropanol might affect the very small gel porosity of the $\mathrm{C}-\mathrm{S}-\mathrm{H}[14]$. Comparison with past results shows the critical or threshold pore entry sizes to be more than one order of magnitude larger for oven dried samples than for samples dried by solvent exchange. Despite these limitations, MIP is one of the most repeatable quantitative techniques for characterizing the pore structure of cementitious materials [15].

Recently, the use of ${ }^{1} \mathrm{H}$ nuclear magnetic resonance (NMR) has led to new insights on the pore structure of cement paste [16]. The major advantage of this technique is that no prior drying is required [17]; indeed the water is itself the probe. This technique has identified three distinct "pore" populations in cement pastes-interlayer water between the layers of the C-S-H (which may not really be regarded as porosity), gel pores in the $\mathrm{C}-\mathrm{S}-\mathrm{H}$, and capillary pores. The capillary pore volume 
Table 1

Chemical composition of the materials.

\begin{tabular}{lccccc}
\hline \multicolumn{6}{l}{ XRF analysis (wt.\%) } \\
\hline & PC & Quartz & Slag 1 & Slag 2 & Fly ash \\
\hline $\mathrm{SiO}_{2}$ & 14.85 & 97.91 & 35.72 & 34.09 & 50.54 \\
$\mathrm{Al}_{2} \mathrm{O}_{3}$ & 2.5 & 1 & 11.94 & 19.87 & 24.7 \\
$\mathrm{CaO}$ & 62.43 & & 41.38 & 33.01 & 5.07 \\
$\mathrm{MgO}$ & 2.05 & & 7.45 & 9.73 & 2.88 \\
$\mathrm{Fe}_{2} \mathrm{O}_{3}$ & 3.11 & & 0.84 & 0.45 & 9.29 \\
$\mathrm{Na}_{2} \mathrm{O}$ & 2.76 & & 0.26 & 0.25 & 1.05 \\
$\mathrm{~K}_{2} \mathrm{O}$ & 3.82 & & 0.27 & 0.84 & 4.1 \\
$\mathrm{TiO}_{2}$ & 0.29 & & 0.51 & 0.9 & 0.95 \\
$\mathrm{SO}_{3}$ & 5.54 & & 1.38 & 0.75 & 0.71 \\
\hline
\end{tabular}

decreases rapidly during the first few days of hydration. However, while the volume of capillary pores continues to decrease, their size seems to plateau at a value of around $8-10 \mathrm{~nm}$ after a few days. At the same time the amount of gel porosity stops increasing, implying formation of a more compact product by an increase in the bulk "density" of the C-S-H gel.

In general blended cement systems have a higher total porosity at early age compared to plain Portland cement (PC) caused by the lower clinker content and the slow reaction of the SCMs $[6,15]$. At later ages the effect of slag and fly ash on the total porosity is not clear from the literature. Generally, studies report similar or smaller pore entry sizes for blended cements $[6,8,15,18]$, but the vast majority of studies used severe drying methods. Nevertheless, earlier studies indicate that there is an optimal replacement of SCM above which the refinement and the reduction of the pore volume are not occurring [19] which, as a consequence, decreases the mechanical properties of the paste $[20,21]$. It has also been reported that the degree of reaction of fly ash $[19,22,23]$ or slag [5] may decrease when they are present at higher replacement levels.

This paper reports on the development of the pore structure in slagPC and fly ash-PC systems and on the filling ability of the hydrates from SCM reaction. For the first time we isolate the effect of SCM in the cement paste by using ternary systems combining PC, quartz, and SCM. Our results show how the major SCM (slag and fly ash) and clinker components influence each other and lead to different filling ability. This study brings new insights on the reactivity of SCM and on the development of microstructure of blended systems.

\section{Materials and methods}

\subsection{Materials}

\subsubsection{Blended systems with SCM-quartz-cement}

Portland cement (CEM I 52.5R) was mixed with quartz and SCM (slag or fly ash). The chemical compositions by XRF are given in

Table 2

Phase composition.

\begin{tabular}{|c|c|c|c|c|c|}
\hline \multicolumn{6}{|c|}{ Phase composition (wt.\%) } \\
\hline & PC & Quartz & Slag 1 & Slag 2 & Fly ash \\
\hline $\mathrm{C}_{3} \mathrm{~S}$ & 69 & & & & \\
\hline $\mathrm{C}_{2} \mathrm{~S}$ & 4 & & & & \\
\hline $\mathrm{C}_{3}$ Acubic & 1.3 & & & & \\
\hline $\mathrm{C}_{3}$ Aortho & 2.6 & & & & \\
\hline $\mathrm{C}_{4} \mathrm{AF}$ & 10 & & & & \\
\hline Calcite & 1.5 & & 0.8 & & \\
\hline Gypsum & 1.3 & & & & \\
\hline Other & 4.6 & & & & \\
\hline Quartz & & 99.0 & 0.1 & & 20 \\
\hline Mullite & & 1.0 & & & 19 \\
\hline Melilite & & & & 5.0 & \\
\hline Amorphous & & & 99 & 94.5 & 61 \\
\hline
\end{tabular}

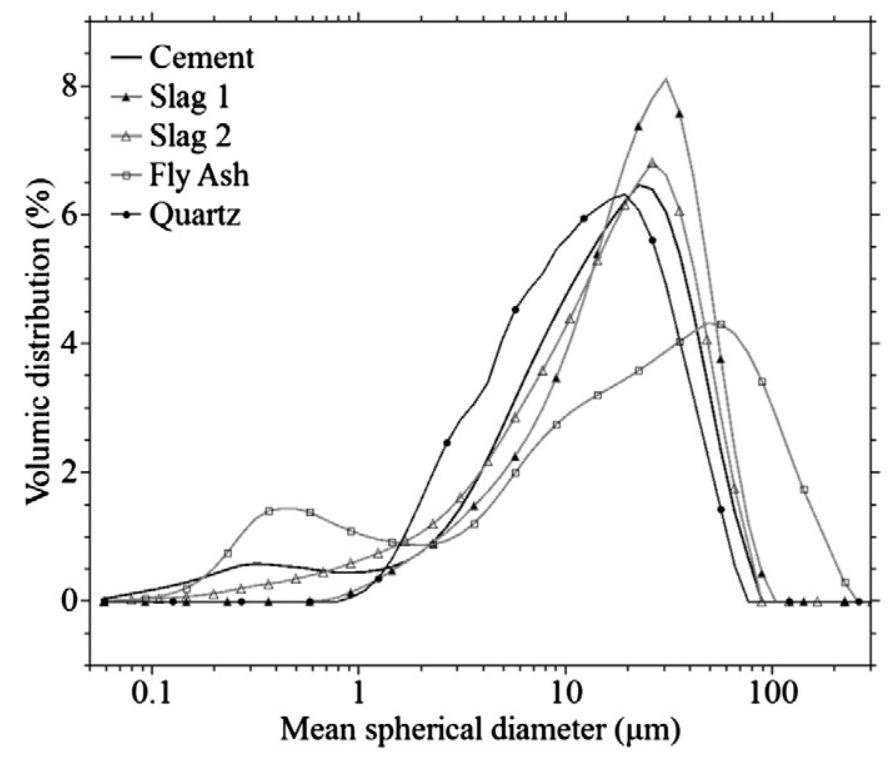

Fig. 1. Particle size distribution of the materials used determined by laser diffraction.

Table 1 and the phase compositions are shown in Table 2. All the powders have close particle size distributions to provide similar filler effects [24] (Fig. 1). At later ages the slightly coarser fineness of fly ash does not affect the results as the systems were designed to have similar volume of solids based on the density of the materials used (Table 3).

To investigate the effect of slag and fly ash and their interaction with cement, we use five systems with $40 \%$ replacement varying the proportion of the SCM and the quartz. This method isolates the effect of the SCM reaction as quartz used was inert. All the systems were formulated to have a solid to liquid volume ratio the same as in a pure Portland cement paste at a water/cement ratio (by weight) of 0.4 . Thus all the systems have the same volume to fill. The volume of the Portland cement was equivalent to $60 \%$ by weight of cement in a mixture of plain Portland cement with a water/cement $=0.4$ (by weight). The remaining 40\% Portland cement volume was replaced by an equivalent volume of SCM or quartz such as 30\% Fly ash + 10\% Quartz, 20\% Fly ash $+20 \%$ Quartz, 10\% Fly ash $+30 \%$ Quartz and 40\% Quartz as a reference. The relative amounts of SCM or quartz are expressed as the equivalent volume of Portland cement replaced. To further explore the effect of the space, pastes with $40 \%$ slag and $40 \%$ Fly ash were also used with different water/solids ratios from 0.4 to 0.6 (i.e. solids means PC + Quartz + SCM). Full details of the all mixtures are given in Table 4.

\subsection{Methods}

\subsubsection{Preparation of pastes}

Prior to hydration, the anhydrous cement was mixed with the mineral substitution (i.e. quartz, slag, fly ash) in a Turbula blender (Willy A. Bachofen AG, Switzerland) to obtain a homogeneous blend. The turbula blended turns in the three dimensional motions (rotation, translation, inversion) the anhydrous solids in a removable container for $30 \mathrm{~min}$. This time is sufficient to ensure homogeneity as verified by repeat measurements. About $80 \mathrm{~g}$ of this anhydrous blend were removed to be mixed with deionized water (except when mentioned) at the water/ solids ratio 0.4 (weight ratio for plain Portland with equivalent

Table 3

Density of the materials used.

\begin{tabular}{llllll}
\hline & PC & Quartz & Slag 1 & Slag 2 & Fly ash \\
\hline Density $\left(\mathrm{g} / \mathrm{cm}^{3}\right)$ & 3.28 & 2.65 & 2.95 & 2.95 & 2.5 \\
\hline
\end{tabular}


Table 4

Mix designs.

\begin{tabular}{|c|c|c|c|c|c|c|c|c|c|c|}
\hline \multirow[t]{2}{*}{ Systems } & \multicolumn{5}{|l|}{ \%weight } & \multicolumn{5}{|c|}{ \%volume } \\
\hline & Clinker & Slag & Quartz & Water & $\mathrm{w} / \mathrm{s}$ & Clinker & Slag & Quartz & Water & $\mathrm{w} / \mathrm{s}$ \\
\hline PC & 71.4 & - & - & 28.6 & 0.4 & 43.1 & - & - & 56.9 & 1.32 \\
\hline PC & 62.5 & - & - & 37.5 & 0.6 & 33.6 & - & - & 66.4 & 1.98 \\
\hline PC 40\%Slag & 44.2 & 26.3 & - & 29.5 & 0.4 & 25.9 & 17.2 & - & 56.9 & 1.32 \\
\hline PC 40\% Slag & 38.6 & 23 & - & 38.6 & 0.6 & 20.6 & 13 & - & 66.4 & 1.98 \\
\hline PC 30\% Slag-10\% Quartz & 44.5 & 19.9 & 6.0 & 29.7 & 0.4 & 25.9 & 12.9 & 4.3 & 56.9 & 1.32 \\
\hline PC 20\% Slag-20\% Quartz & 44.8 & 13.3 & 12.0 & 29.9 & 0.4 & 25.9 & 8.6 & 8.6 & 56.9 & 1.32 \\
\hline PC 10\% Slag-30\% Quartz & 45.1 & 6.7 & 18.1 & 30.1 & 0.4 & 25.9 & 4.3 & 12.9 & 56.9 & 1.32 \\
\hline PC $40 \%$ Quartz & 45.4 & - & 24.3 & 30.3 & 0.4 & 25.9 & - & 17.2 & 56.9 & 1.32 \\
\hline
\end{tabular}

volumetric replacement by SCM as described previously). The pastes were mixed at $1600 \mathrm{rpm}$ for $2 \mathrm{~min}$. The temperature after the mixing procedure was slight increase $\left(20^{\circ} \mathrm{C}\right.$ to $\left.22{ }^{\circ} \mathrm{C}\right)$. This rise does not have significant effect on the kinetics at later ages [25]. Furthermore for comparison purpose, all the systems were mixed in similar conditions.

The pastes were cured underwater at $20^{\circ} \mathrm{C}$. After 4 days the curing temperature for the fly ash-quartz-cement pastes was increased to $30{ }^{\circ} \mathrm{C}$ to enhance the reaction. It is known that hydration at higher temperatures can change the characteristics of the $\mathrm{C}-\mathrm{S}-\mathrm{H}$ [26] but this impact is most pronounced at early ages. After 4 days the impact of the increase in temperature is not expected to have a major effect on the $\mathrm{C}-\mathrm{S}-\mathrm{H}$ from the clinker hydration as the degree of hydration of the clinker is typically $>60 \%$ (Fig. 4 ).

\subsubsection{Kinetics of hydration by isothermal calorimetry}

The hydration was followed by calorimetry (TAM Air, TA Instruments). Ten grams of paste were placed in the calorimeter. The instrument was maintained in a temperature controlled room $\left(20^{\circ} \mathrm{C}\right)$ to ensure the stability of the baseline. The heat flow was recorded up to 28 days. Calorimetry measures heat flow which becomes very low after a few days (with increased relative measurement error). This means that the cumulative heat evolved which is proportional to the degree of hydration is not reliable beyond about 28 days. Nevertheless it has been verified that under the operational conditions used (stable room temperature, calibrated baseline, heat capacity equivalent reference) the cumulative heat can be calculated with reasonable accuracy up to 28 days [27].

\subsubsection{X-ray diffraction}

The samples were cast in plastic bottles and kept at room temperature. One slice of the hardened paste cylinder was cut at the required hydration time and immediately inserted in the XRD holder (i.e. measurements on fresh paste). Standard XRD measurements were carried out with a Panalytical X'Pert Pro MPD diffractometer in a $\theta-\theta$ configuration using CuK $\alpha$ source with a fixed divergence slit size of $0.5^{\circ}$. The $\mathrm{X}$-ray tube was operated at $45 \mathrm{kV}$ and $40 \mathrm{~mA}$. The slice was scanned on a rotating stage between 4 and $65\left[^{\circ} 2 \theta\right]$ using an X'Celerator detector with a step size of $0.0167^{\circ} 2 \theta$ and a time per step of 30s. The measurement lasts about $20 \mathrm{~min}$ and still the slice was near saturated after the test.

Phase identification and Rietveld quantitative phase analysis were carried out using the X'Pert High Score Plus software by PANalytical. The external standard method was used as main method to quantify the phase content. The degree of hydration of the cement was calculated as follows

$\alpha(t)=1-\frac{W_{\text {anhydrous }}(t)}{W_{\text {anhydrous }}(t=0)}$

where $W_{\text {anhydrous }}(t)$ is the weight fraction of the anhydrous clinker phases calculated with correction of the dilution effect such as
$W_{\text {anhydrous }}=W_{\text {anhydrous diluted }} \times\left(1+{ }^{w} / c\right)$ and $W_{\text {anhydrous }}(t=0)$ is the initial weight fraction of the anhydrous clinker phases.

\subsubsection{Mercury intrusion porosimetry}

A mercury intrusion porosimeter from Thermoscience (Pascal 140/ 440) was used. Fresh paste was cast into capsules (35 mm diameter, $50 \mathrm{~mm}$ height) cured under water and stored at $20^{\circ} \mathrm{C}$. At the required time of hydration, a slice ( $2 \mathrm{~mm}$ thick) of the hardened paste was cut. Then hydration was stopped by isopropanol exchange to preserve the microstructure [9]. The slice was dried with a continuous pumping under vacuum for 1 day to remove all the isopropanol and then kept under vacuum for 1 week. The dried samples were placed in the sample container and the air was removed. The pressure was increased up to $400 \mathrm{MPa}$ which allows intrusion of pore entries down to nominally $2 \mathrm{~nm}$ radius (assuming a contact angle of $140^{\circ}$ ). Fig. 2 shows typical results from the MIP analysis. Two repetitions from the same sample are shown which illustrates the excellent repeatability of the method. Two depictions of the results are used in this study: the cumulative pore volume curve and the pore entry size distribution. The first one is deduced from the intruded volume of mercury and gives the total connected pore volume in the entire specimen. This value can be read from the cumulative porosity for the smallest pore (i.e. the highest pressure).

The differential distribution curve is calculated from the cumulative pore volume curve. This plot has the advantage of clearly showing the "critical" radius of the sample which is the inflexion point in the cumulative curve and corresponds to the maximum of the sharp peak as described in the Fig. 2 . In this study this critical radius was used to

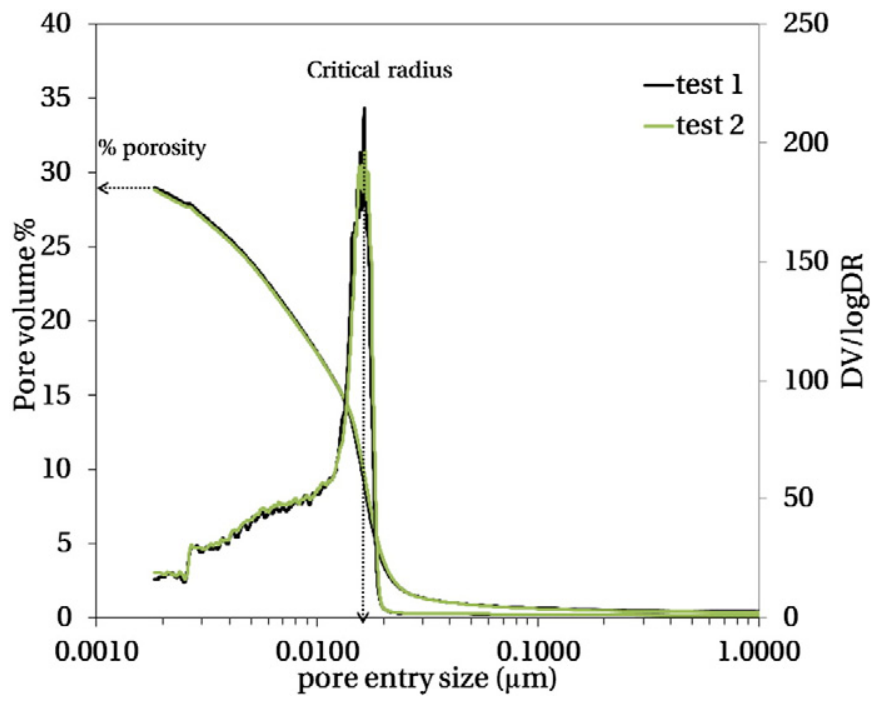

Fig. 2. Example of typical MIP cumulative and derivative curves obtained when measuring cement pastes with a maximum MIP pressure of $400 \mathrm{MPa}$. The three principal characteristic values of MIP results are identified as the total pore volume and the critical pore entry radius. 

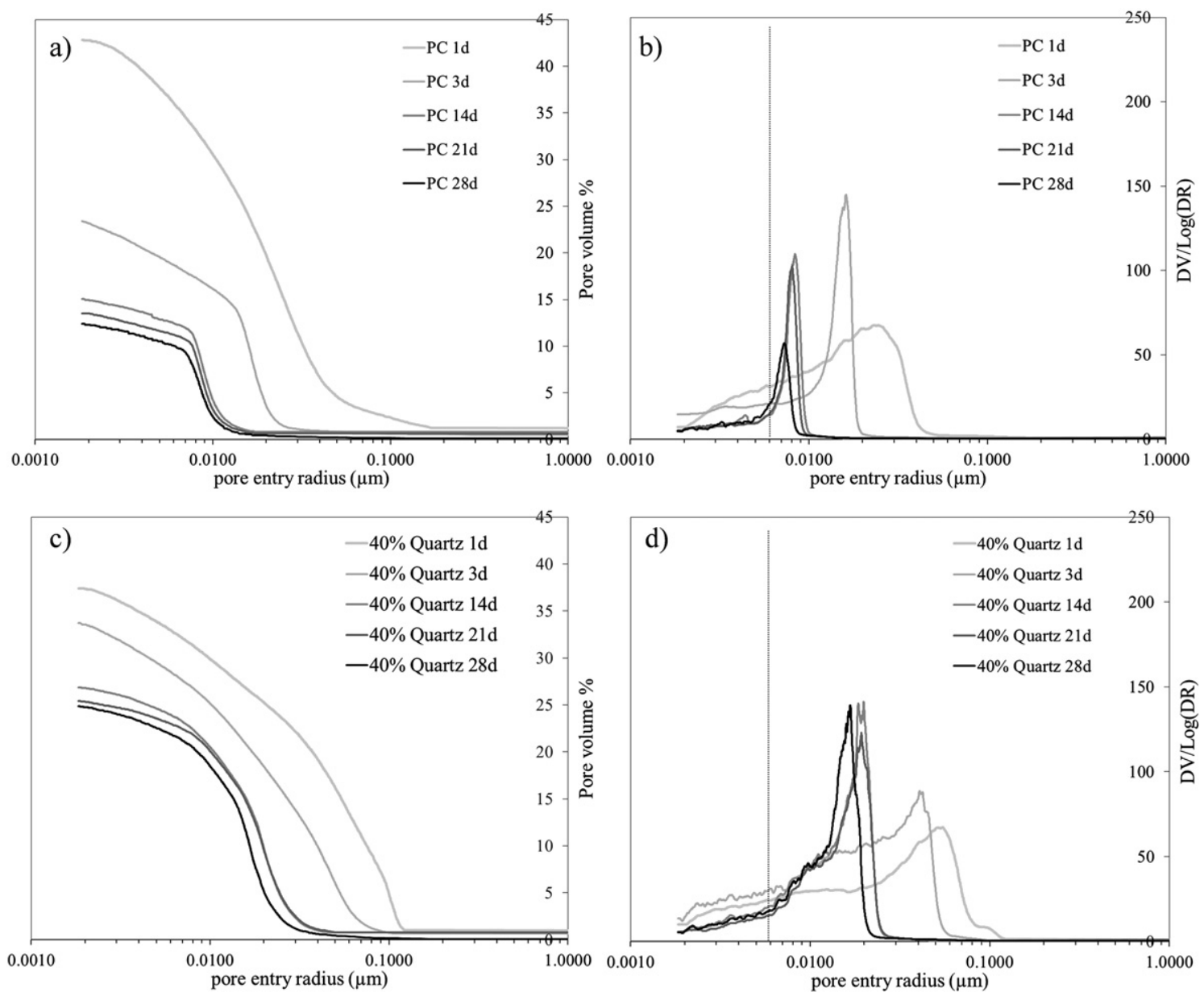

Fig. 3. Cumulative and derivative curve of the pore structure from MIP measurements a) and b) PC; c) and d) $40 \% Q u a r t z-P C$.

characterize the pore entry size of the connected porosity rather than the start of the upturn in the cumulative plot (or threshold size) as it can be measured more accurately.

\subsubsection{Microstructural observations}

The microstructures were observed with a scanning electron microscope from FEI (quanta 200) with an accelerating voltage of $15 \mathrm{kV}$ and a Bruker AXS XFlash Detector for energy-dispersive X-ray analyses. Backscatter electron (BSE) images of polished surfaces were collected to distinguish the different phases present in the microstructure by their phase contrast. The pastes were prepared according to the procedure described in the previous section. The method to stop the hydration was the isopropanol exchange that cause less damage to the microstructure than others techniques. After the removal from isopropanol, the slide of paste was dried under vacuum for 1 day. Then, the sample was prepared for BSE observation by epoxy resin impregnation (EPOTEK-301) and polished with diamond powders down to $1 \mu \mathrm{m}$. Samples were coated with about $15 \mathrm{~nm}$ carbon prior SEM observation.

\section{Results}

\subsection{Pore structure of plain Portland cement paste}

Fig. 3.a) and b) shows the MIP curves of the plain Portland paste up to 28 days. The pore volume intruded by mercury and the critical radius both decrease with curing time as the hydrates fill the pores. The pore volume decreases rapidly within the first 14 days and then decreases more slowly. The distribution of pore entry size in Fig. 3.b) shows at 1 day a broad peak which becomes sharper at 3 days. From 14 days the critical pore entry size remains near constant. The stabilization of the critical pore entry size corresponds well to the findings from ${ }^{1} \mathrm{H}$ NMR mentioned in the introduction. The stabilization in size seems to occur somewhat later than seen in Ref. [28], this may be explained by the different cement used and the fact that the samples are cured under water here rather than sealed as in the NMR study.

The replacement of cement by inert filler such as quartz leads to an increase of the water/cement ratio in the paste. Fig. 3.c) and d) shows

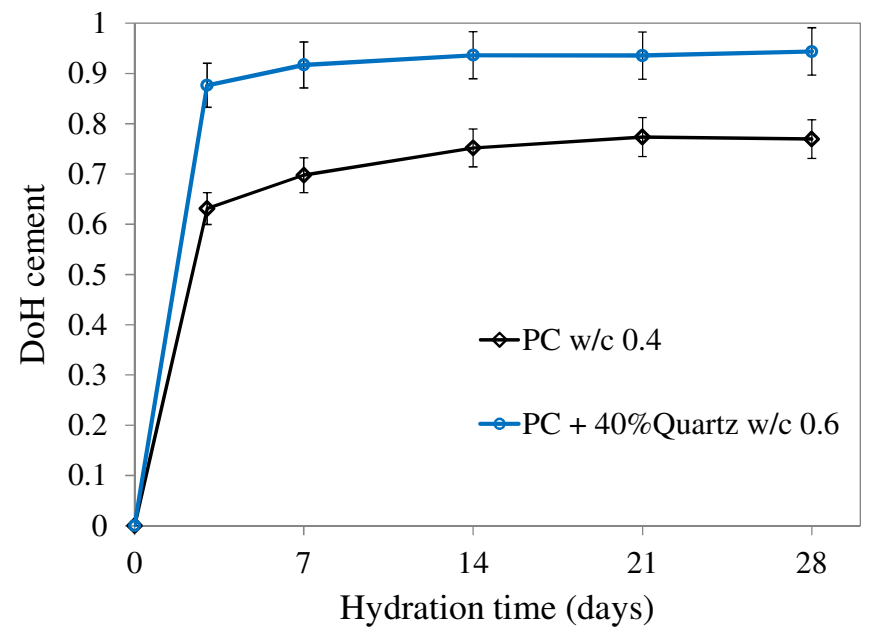

Fig. 4. Degree of hydration of cement in PC w/s 0.4 and PC 40\% Quartz determined by Rietveld analysis. 

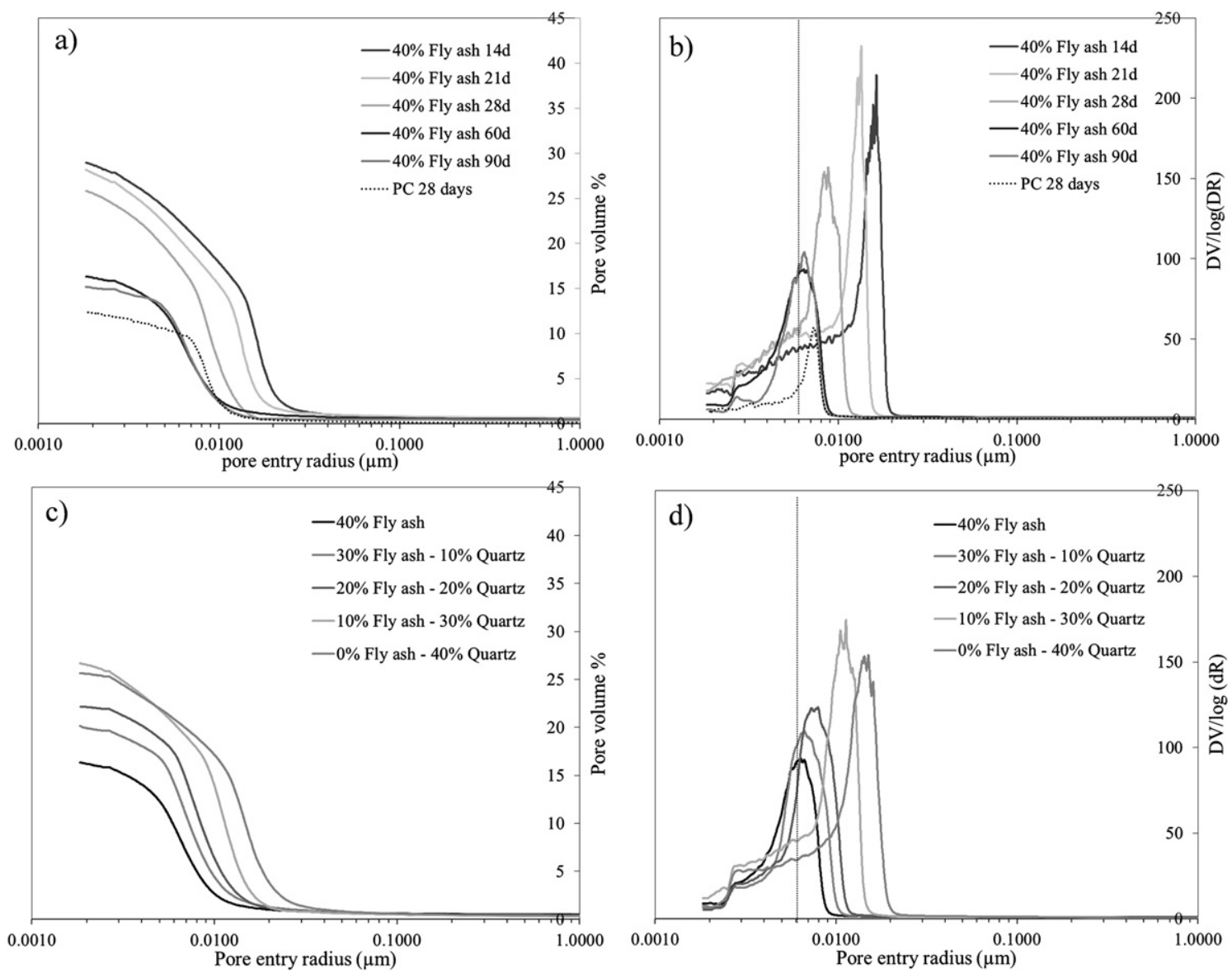

Fig. 5. MIP curves of a) and b) fly ash-PC systems from 21 to 60 days and c) and d) fly ash-quartz-PC systems at 60 days.

this effect of dilution of the clinker phases on the MIP curves. There is a larger pore volume intruded and the critical radius is higher. In the differentiated curve Fig. 3.d) the peak is less pronounced and broader. The transition to a narrower peak seems to occur later than for PC as the narrow peak is still not well defined at 3 days. After 14 days the critical radius and the pore volume do not decrease much. Fig. 4 shows that the degree of hydration of cement in quartz PC system is near $100 \%$. Consequently there is no more clinker in this system to further hydrate and fill the pore space.

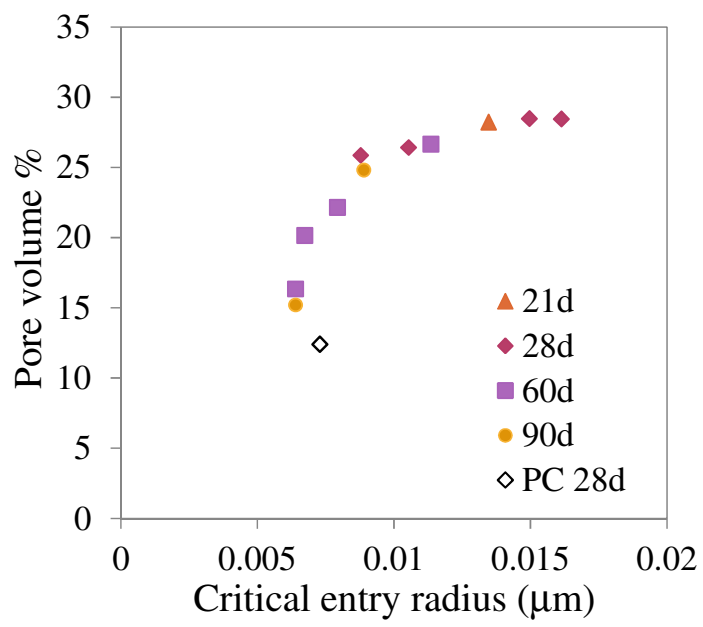

Fig. 6. Evolution of the pore volume as a function of the critical entry radius of the ternary systems containing fly ash.

\subsection{Effect of fly ash on cement hydration}

Fig. 5.a) and b) shows the pore structure development of the $40 \%$ fly ash + PC system during hydration. The first observation is that up to 21 days the pore volume and the pore size distribution of the system are similar to the system with $40 \%$ Quartz + PC. Thus the reaction of the fly ash seems not to have a significant impact on the porosity until 14-21 days. By 28 days the contribution of the fly ash is more evident on the MIP curves. The peak of the size distribution curve becomes

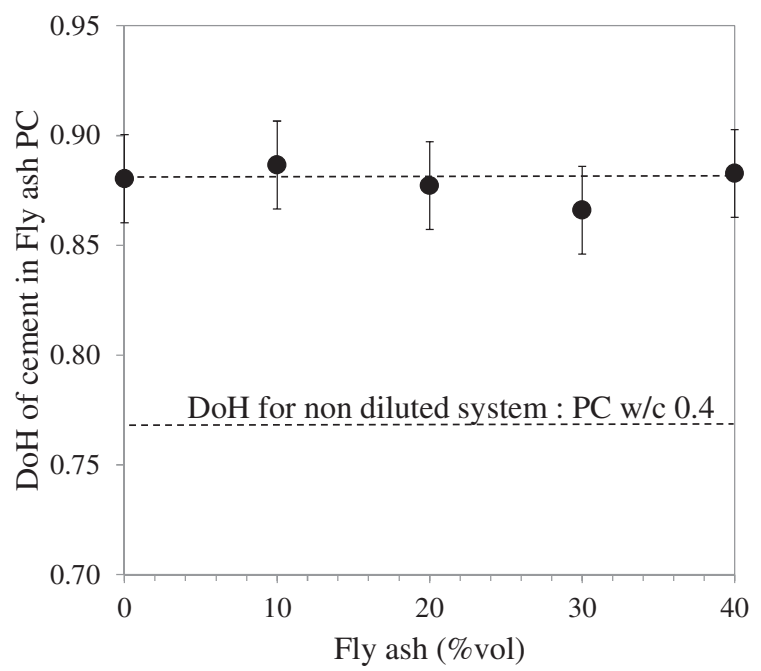

Fig. 7. Degree of hydration of cement determined by Rietveld analysis in the quartz-fly ash-PC systems at 28 days. 


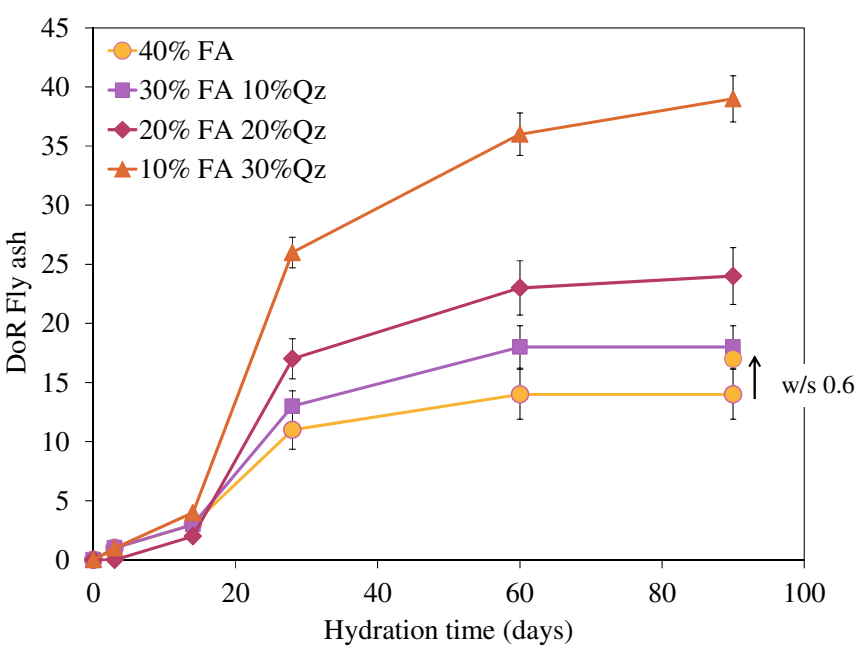

Fig. 8. Degree of reaction of fly ash up to 90 days. NB $40 \%$ of the fly ash is inert phase.

narrower as for PC systems. The pozzolanic reaction from fly ash seems to start to overcome the dilution effect of the replacement at this stage. At 60 and 90 days the critical radius remains near constant that indicates a slow-down of the fly ash reaction. The window of time over which the fly ash affects the pore structure is quite short.

Fig. 6 summarizes the effect of fly ash on the pore structure. Increasing the fly ash proportion in the systems PC-fly ash-quartz reduces the porosity and shifts the critical radius to smaller sizes. However the pore volume does not decrease linearly with the critical radius. Fig. 6 shows that the critical radius becomes limited to a minimum size of about $6 \mathrm{~nm}$ while the pore volume continues to decrease with time. The size of the minimal critical radius is similar to that of the PC system (about $7 \mathrm{~nm}$ ).

Fig. 7 shows that the degree of hydration of cement measured by XRD is not affected by the presence of fly ash at 28 days: varying the proportions of fly ash and quartz in the PC-fly ash-quartz system does not change the degree of hydration of cement. The cement hydration is, however, increased compared to plain PC system. This is due to the dilution by filler: the water/cement ratio is increased to 0.6 as $40 \%$ of the Portland cement is replaced by fly ash.

The degree of reaction of fly ash was estimated from the consumption of portlandite measured by TGA technique assuming the following pozzolanic reaction:

$$
\begin{aligned}
& C_{0.1} A_{0.29} S_{1}+(x+3(0.29-y)-0.1) C H+H \rightarrow C_{x} A_{y} S H \\
& \quad+(0.29-y) C_{3} A X H
\end{aligned}
$$

where $\mathrm{C}_{0.1} \mathrm{~A}_{0.29} \mathrm{~S}$ represents the chemical composition of fly ash, $\mathrm{x}$ is the $\mathrm{Ca} / \mathrm{Si}$ ratio and $\mathrm{y}$ is $\mathrm{Al} / \mathrm{Si}$ ratio of outer $\mathrm{C}-\mathrm{S}-\mathrm{H}$ at 28 days. Both ratios were calculated from EDX measurements and are respectively 1.56 and 0.13 .

The degree of reaction of fly ash includes the amount of phases that should not react such as quartz and mullite. These phases represent from Table 2 , about $40 \%$ of the fly ash composition. Therefore a maximum of $60 \%$ of the overall fly ash may react.

This calculation will somewhat underestimate the degree of reaction as it does not take into account the calcium coming from the $\mathrm{C}-\mathrm{S}-\mathrm{H}$ initially formed by the reaction of the clinker phases which will have a $\mathrm{Ca} / \mathrm{Si}$ ratio of around 1.7-1.8 [29]. Nevertheless it is sufficient for comparative purposes.

The reaction of fly ash is very low in all the systems up to 14 days, even for curing at $30{ }^{\circ} \mathrm{C}$ from 4 days (Fig. 8). From 14 to 28 days there is $10-20 \%$ reaction of the fly ash with the amount depending strongly on the amount of fly ash in the systems. The degree of reaction of the system containing only $10 \%$ fly ash is roughly twice that in the system containing $40 \%$ fly ash. At 60 and 90 days the degree of reaction continues to increase for the systems with low fly ash content, but very little for those with high fly ash content. Furthermore for the $40 \%$ fly ash system at w/c equivalent of 0.6 the degree of reaction at 90 days is significantly higher. These observations indicate that the reaction of the fly ash becomes limited by lack of space. Substantial amounts of calcium hydroxide (around 15\%) remain even in the systems with the highest fly ash content.

The evolution of the reaction of the fly ash does not correlate in a straightforward way with the changes in porosity described above. From 14 to 28 days there is substantial reaction of the fly ash and a significant reduction in the critical pore entry size ( $16 \mathrm{~nm}$ to $9 \mathrm{~nm}$ ). However the reduction in the total porosity measurable by MIP is relatively modest (Fig. 5). On the contrary from 28 to 60 days there is little further reaction of the fly ash, there is a slight reduction in the critical pore entry ( $9 \mathrm{~nm}-6 \mathrm{~nm}$ ) but the total pore volume almost halves (Fig. 5). After 60 days there is almost no further reaction of fly ash in the $40 \%$ fly ash system as it seems the critical pore entry radius cannot be reduced further.

Fig. 9 compares BSE images of the microstructure of the $10 \%$ fly ash $+30 \%$ Quartz PC (degree of fly ash reaction not limited) and $40 \%$ fly ash PC systems (limited degree of reaction). The microstructures at 28 days differ. Substantial capillary porosity is still evident in the $10 \%$ fly ash $+30 \%$ Quartz system whereas in the 40\% fly ash PC system the microstructure is almost full of hydrates. Virtually the only spaces remaining, in this latter system, are hollow hydration shells from the reaction of small clinker grains. These observations support the supposition that the reaction of fly ash is limited by the lack of capillary pores available for hydrates to deposit in, as the degree of reaction of the fly ash is much higher in the system with a higher amount of water-filled space.

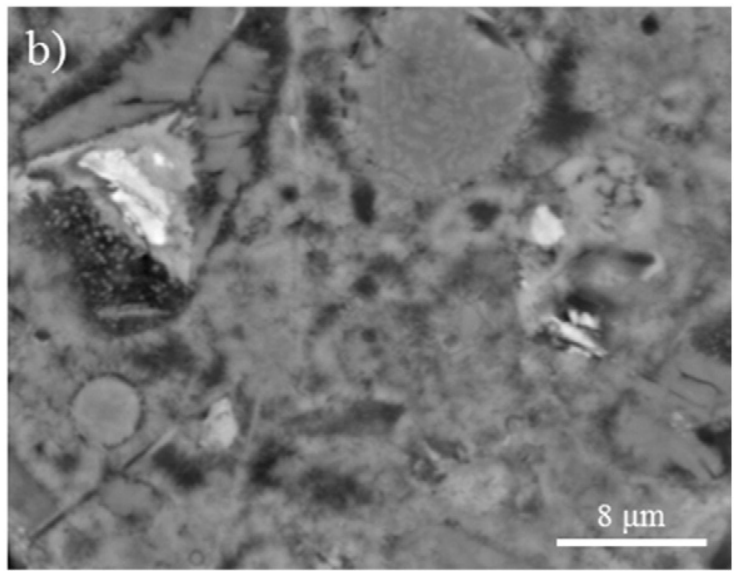



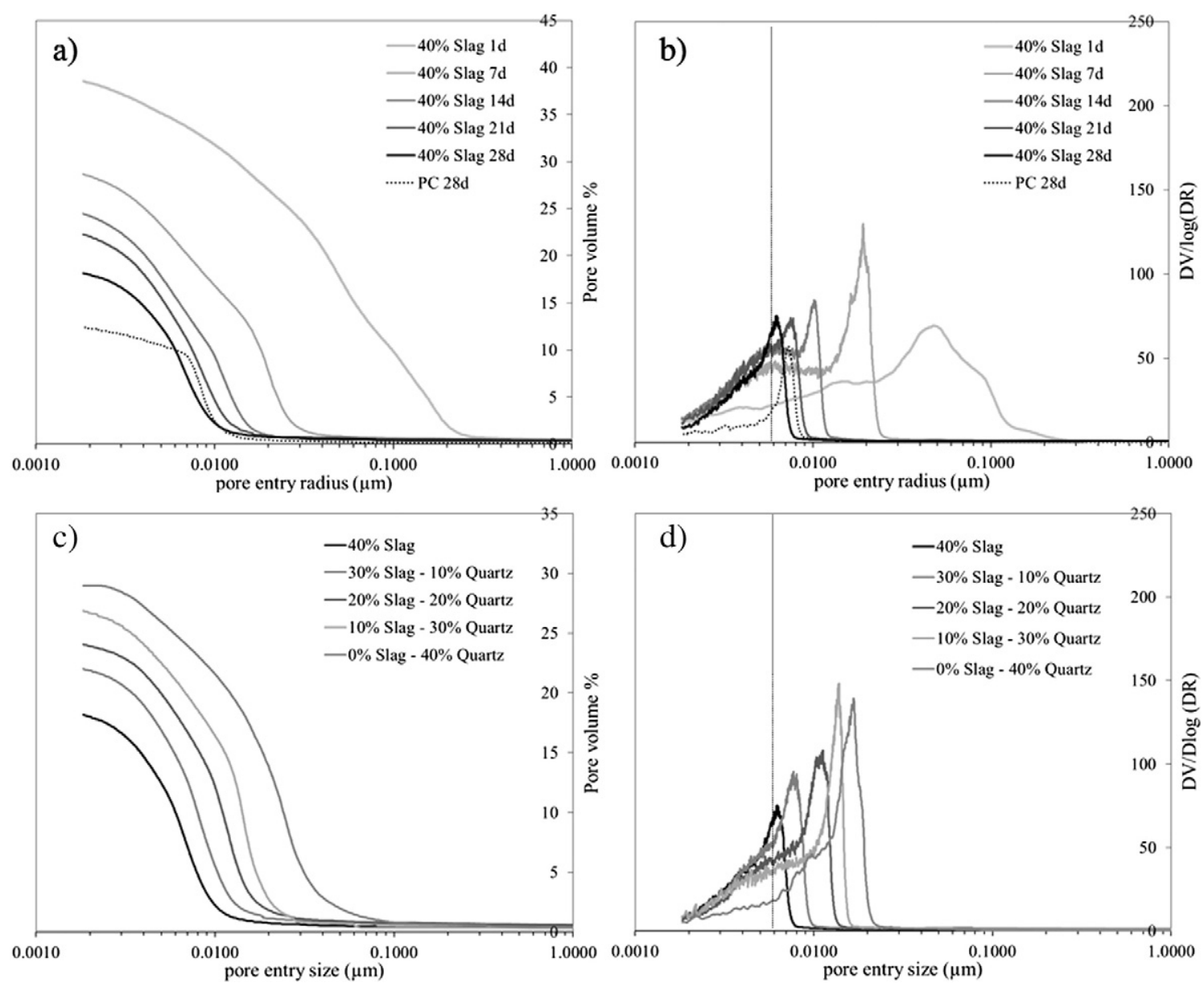

Fig. 10. MIP curves of a) and b) slag cement from 1 to 28 days; c) and d) slag-quartz-cement systems at 28 days.

\subsection{Effect of slag on pore structure}

Fig. 10.a) and b) shows the MIP curves from 1 to 28 days for blended cement with $40 \%$ slag. The pore volume and critical radius decrease with hydration time. Calorimetry (discussed below) indicates that the slag reaction starts at around 2-3 days; by 14 days there is already a very significant effect of the slag reaction in reducing porosity compared to the $40 \%$ Quartz + PC systems (Fig. 10.d). At 28 days the system with $40 \%$ slag shows similar critical radius to that of plain cement paste at the same age even though the total porosity is higher. This indicates that the slag reaction is very efficient in reducing the critical radius to smaller size, i.e. refine the porosity.

The pore size distribution in slag pastes in Fig. 11 is qualitatively different from the curves of the other systems presented previously, i.e. PC, 40\% Quartz PC system, fly ash PC systems. The distribution can be described as a narrow first distribution at a similar pore size to the PC system followed by a plateau covering a large range of smaller pores. The first peak, which is similar to that in PC, could be attributed to the PC hydrates network while the wide range of pores seems to be the result of the slag reaction as it becomes more pronounced when the slag amount is increased (Fig. 10.d). This gives some qualitative indication that the connectivity between the pores in slag system is different than in the cement and in fly ash-PC systems.

Fig. 12.a) summarizes the evolution of the pore volume as a function of the critical entry pore radius of fly ash, slag cement systems compared to Portland cement systems. The slag seems to be more effective in reducing the total porosity as well as the critical pore entry size. However Fig. 12.b) emphasizes clearly that once the critical radius reaches the size of about 6-8 nm, it does not decrease further in size in blended and plain cement systems.

The presence of slag also has a significant effect on the hydration of cement. While increasing the fly ash content does not affect the degree of reaction of cement, it can be seen in Fig. 13 that increasing the level of

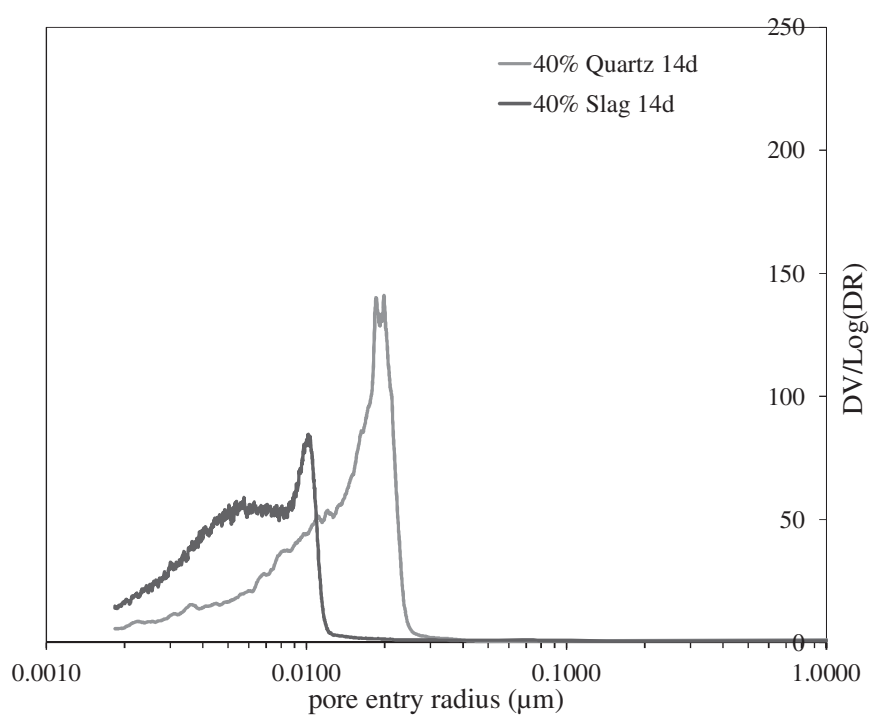

Fig. 11. Comparison of the pore size distribution in $40 \%$ quartz and $40 \%$ slag systems. 
a)

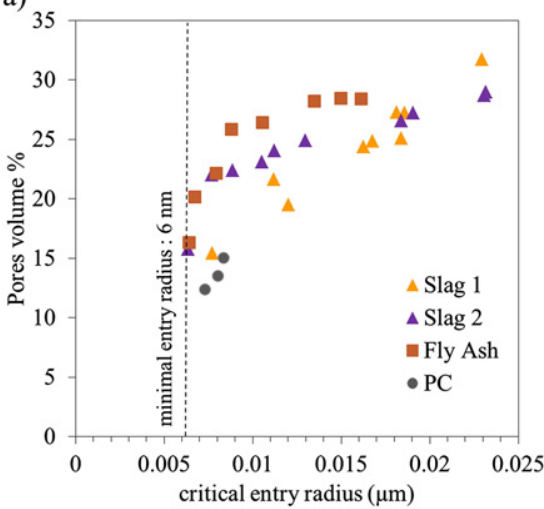

b)

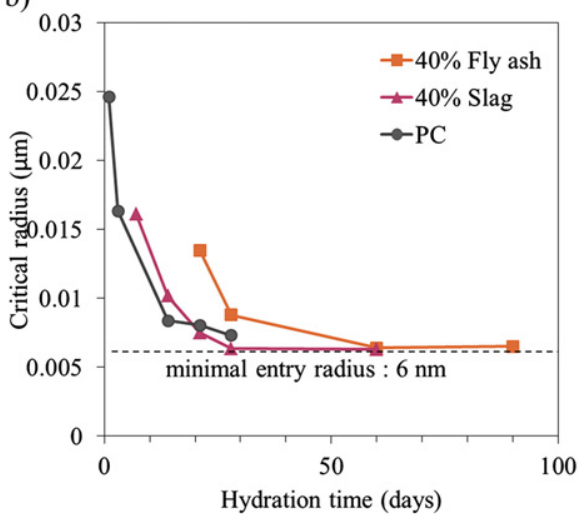

Fig. 12. a) Pore volume in slag-PC, fly ash-PC and PC pastes as a function of the critical radius. b) Critical radius decrease as a function of hydration time.
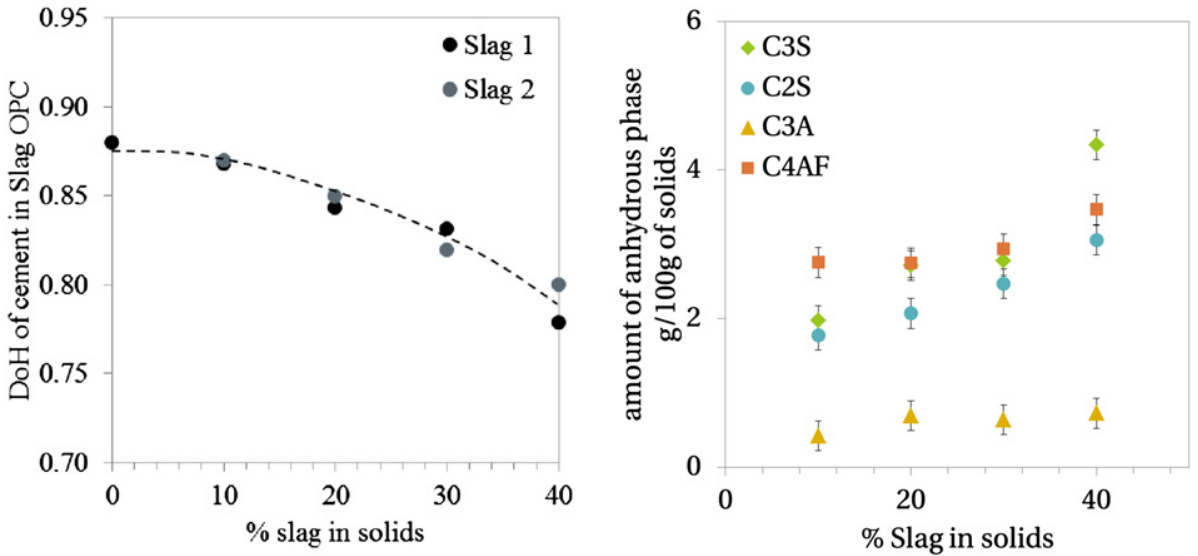

Fig. 13. Degree of hydration of cement in the blended systems calculated from Rietveld analysis.

slag replacement decreases the cement hydration. This might be the result of the lack of space for the cement hydrates at this stage of the hydration.

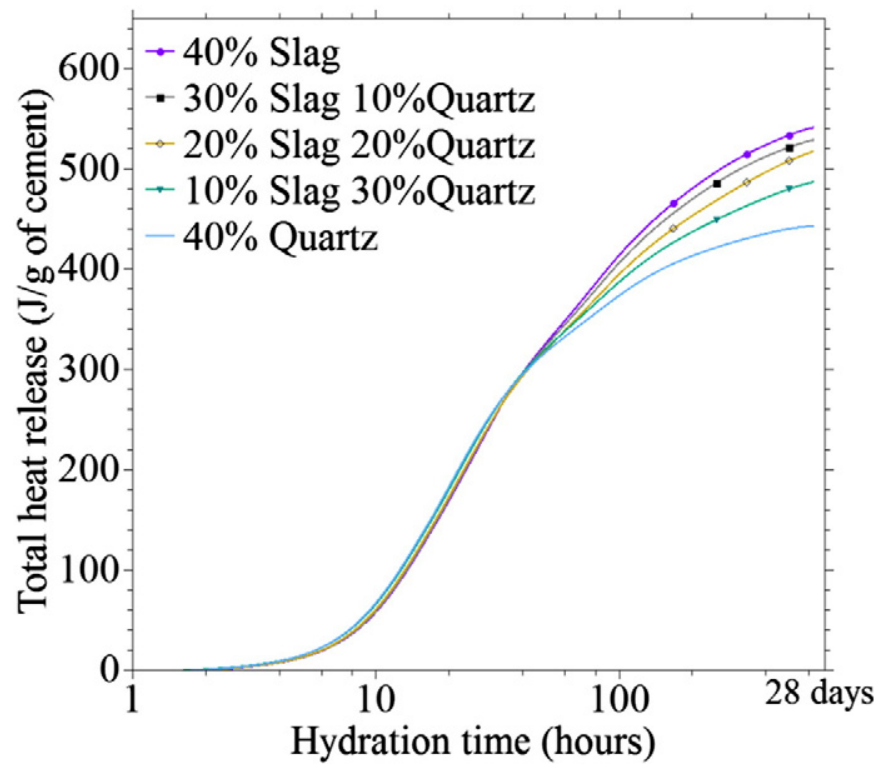

Fig. 14. Calorimetry curves of slag-quartz-cement systems. The cumulative heat becomes limited.
The measure of the slag reaction is quite complex [27]. In this study we made an estimation of the slag reaction based on the heat released from the overall reaction and the degree of hydration of cement. The calculated contribution of slag can be seen as a relative degree of slag reaction in the blend.

Fig. 14 shows the cumulative heat released over 28 days of hydration. The first observation is that the four curves are almost identical up to about $30 \mathrm{~h}$ and then progressively diverge. The total heat reached at 28 days increases with slag content. Nevertheless the additional heat is not proportional to the slag content. For instance at high replacement levels (more than 20\%) the increase is quite small. This suggests that slag reaction becomes limited at higher additions. This is confirmed by Fig. 14 which shows the contribution of slag to the overall cumulative heat of the reaction. It was calculated based on the degree of hydration of the clinker phases previously shown (Fig. 13) and the cumulative heat as shown in the following equation:

$H_{\text {slag }}=\frac{H_{\text {overall }}-H_{\text {cement }}}{m_{\text {slag }}}$
Table 5

Enthalpies of the three major reactions in cement hydration.

\begin{tabular}{ll}
\hline Reaction & $\mathrm{H}(\mathrm{J} / \mathrm{g})$ \\
\hline $\mathrm{C}_{3} \mathrm{~S}$ & 558 \\
$\mathrm{C}_{2} \mathrm{~S}$ & 362 \\
$\mathrm{C}_{3} \mathrm{~A}$ & 747 \\
\hline
\end{tabular}




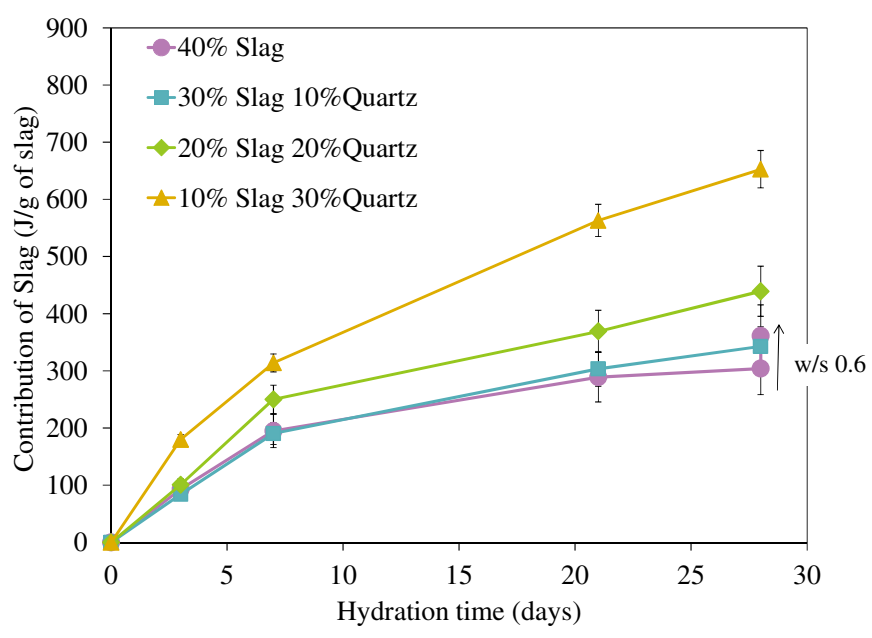

Fig. 15. Slag contribution to the cumulative heat release for the slag-quartz PC systems at $20{ }^{\circ} \mathrm{C}-\mathrm{w} / \mathrm{s} 0.4$ unless otherwise specified.

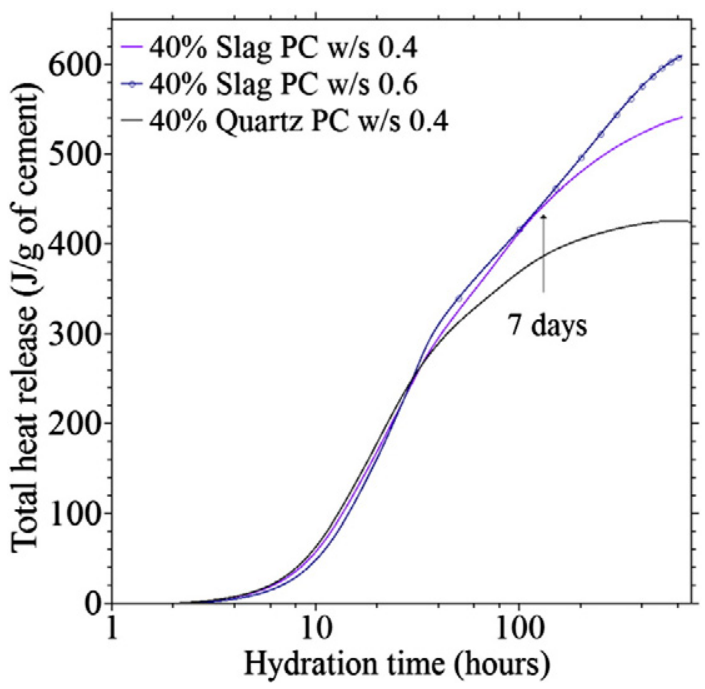

Fig. 16. Effect of increasing water/solid ratio on kinetics.

Where

$\mathrm{H}_{\text {slag }} \quad$ is the heat released from the slag reaction per $\mathrm{g}$ of slag in the blend.

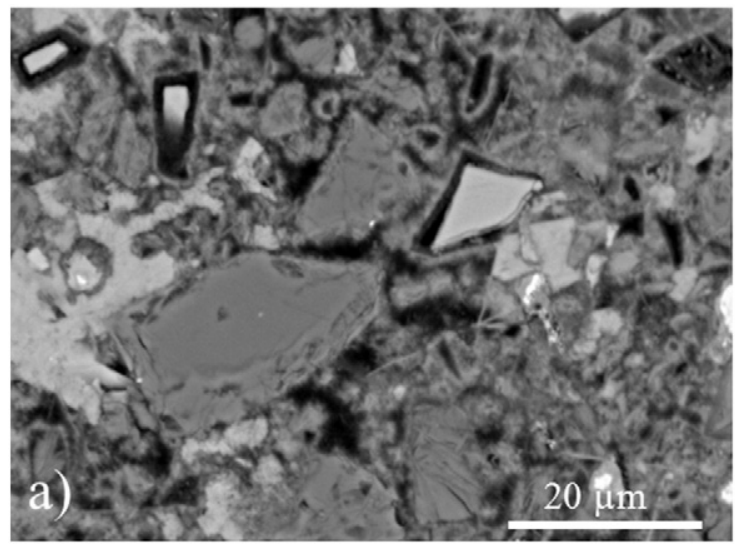

$\mathrm{H}_{\text {overall }}$ is the total heat released from the hydration of the blend. The value is determined from the cumulative heat released recorded by isothermal calorimetry.

$\mathrm{H}_{\text {cement }}$ is the heat released from the hydration of clinker phases as follows:

$H_{\text {cement }}=\sum \Delta_{i} H$

The enthalpy of dissolution of the main clinker phases was estimated based on the amount of $C_{3} S, C_{2} S, C_{3} A$ consumed and their enthalpy found in CEMDATA14 data base [30]. The reactions occurring are assumed to be as follows:

$$
\begin{aligned}
C_{3} S & +3.9 H \rightarrow C_{1.7} S_{2.6}+1.3 C H-2931-3.9 \times 286 \rightarrow-2890-1.3 \\
& \times 986 \Delta_{C 3 S} H=-558 J / g C_{2} S+2.9 H \rightarrow C_{1.7} S_{2.6}+0.3 C C_{3} A \\
& +3 C s+32 H \rightarrow C_{3} A \cdot 3 C s \cdot H_{32}
\end{aligned}
$$

The calculated enthalpies are summarized in Table 5.

The results of the calculations of the slag contribution in Fig. 15 highlight that the slag reaction is limited at higher replacement levels. The slag in the $10 \%$ slag $+30 \%$ quartz PC systems reacts more than in the $40 \%$ slag + PC system from 7 days.

Cumulative curves for water to solids ratios 0.6 and 0.4 are shown in Fig. 16 and can be compared to the quartz reference curve. From 0 to 7 days both systems have similar kinetics, indicating that space is not limiting the reaction during this period. Then from 7 days, we see that the reaction slows down in the lower $\mathrm{w} / \mathrm{s}$ system with less space, while it continues in the higher $\mathrm{w} / \mathrm{s}$ system. This effect indicates that the slowdown of the slag reaction in the $40 \%$ slag paste from 7 days, observed in Fig. 16, is the result of the lack of space.

The micrographs in Fig. 17 support lack of space as the limiting factor. The system where the slag reaction is limited corresponds to the microstructure where no large capillary pores were observed. The only spaces remaining in the $40 \%$ slag-PC are the shells of hydration products from the cement grains (Fig. 17.b). In the 10\% slag $+30 \%$ quartz PC system some large capillary pores are left (Fig. 17.a) and the slag reaction is still ongoing. This is a qualitative observation. The MIP does not indicate such large pores as the shells of hydration are only accessible through smaller pore entries.

\section{Discussion}

Examination of the effect of water to solids ratio on the three systems also underlines the differences between plain cement paste and blends with slag and fly ash. The micrographs in Fig. 18 compare the effect of the water/solids ratio (0.4 and 0.6) for PC, $40 \%$ slag and $40 \%$

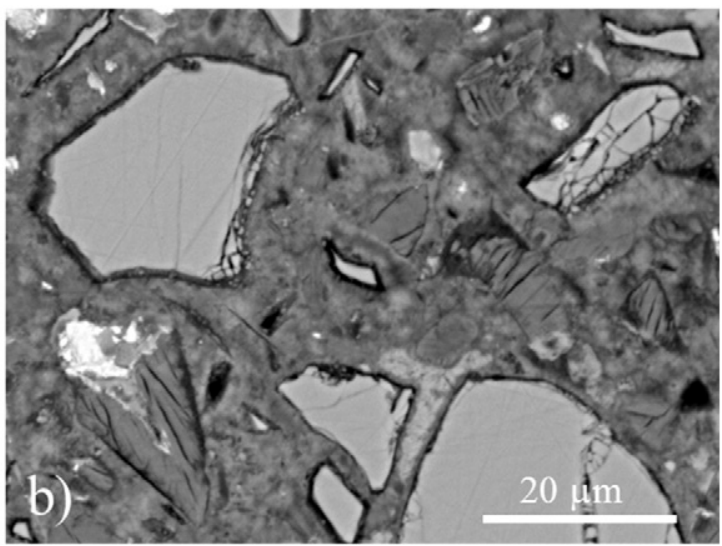

Fig. 17. Micrographs at 28 days a) $10 \%$ slag-30\% quartz cement and b) $40 \%$ slag cement. 
fly ash. The effect of increasing the water/solids ratio is different in the slag/PC blend to the other systems.

For the slag pastes, although the water/solids ratio of 0.6 provides more space, most of the capillary porosity is filled from BSE images and MIP measurements (Figs. 18 and 19). Large clumps of AFm phase are a notable feature in both systems. At higher water/solids $=0.6$, these form in the spaces between particles, whereas in the system with water/solids 0.4 these clumps occur in the shells of hydration product from small cement grains (Hadley grains), which would appear to be the only space available in this case.

These observations are supported by the MIP data in Fig. 19 from the same mixes shown in Fig. 18. At w/s 0.4 the systems all have the same critical pore entry size, while the systems with slag and fly ash have somewhat higher total porosities. When the water/solids ratio increases to 0.6 , the critical pore entry radius increase for all the systems, but much less for the system with slag.
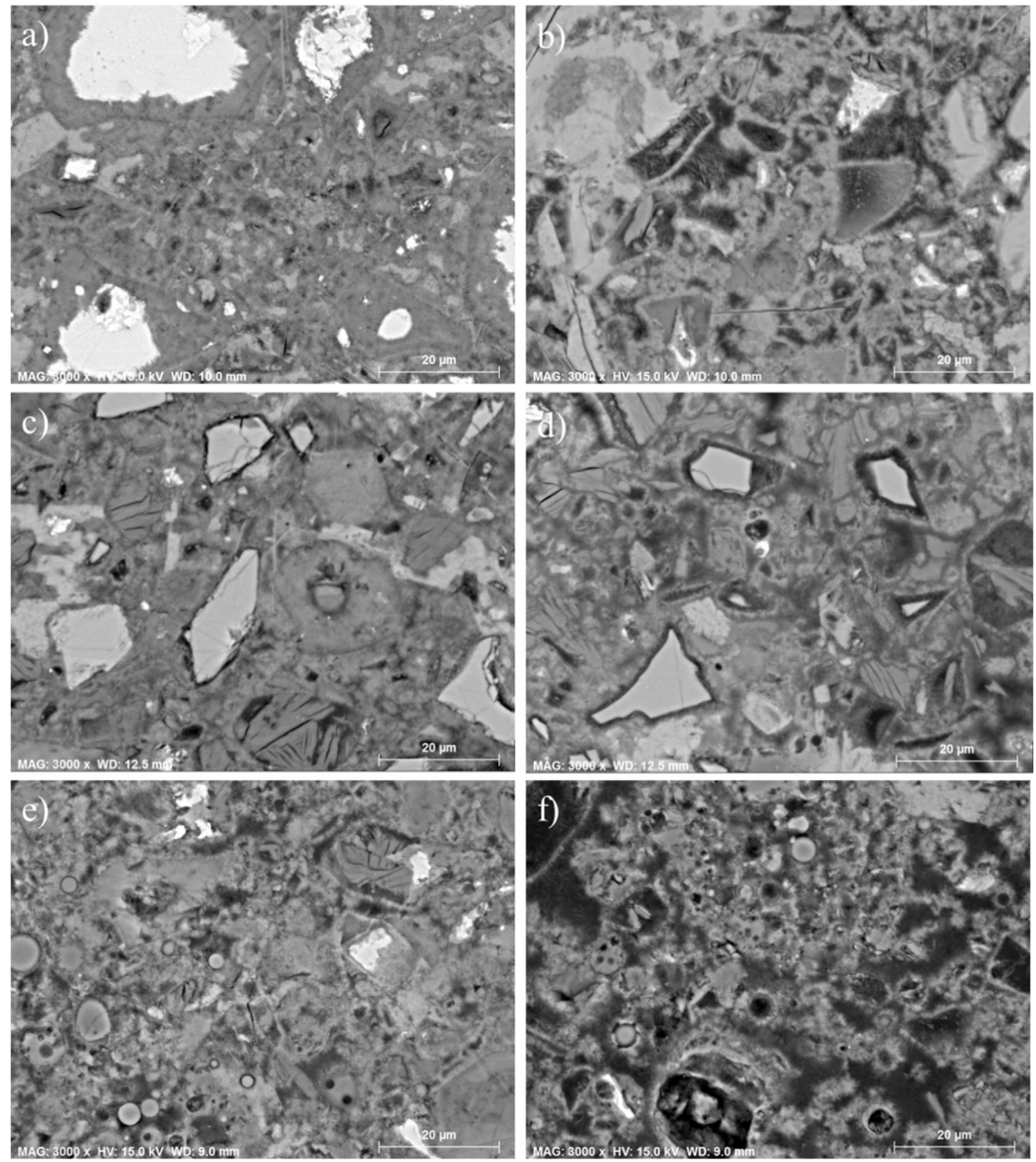

Fig. 18. Microstructure of PC at 28 days: a) w/s 0.4; b) w/s 0.6, 40\% Slag at 28 days; c) w/s 0.4, d) w/s 0.6, 40\% Fly ash; e) w/s 0.4 ; f)w/s 0.6 . 


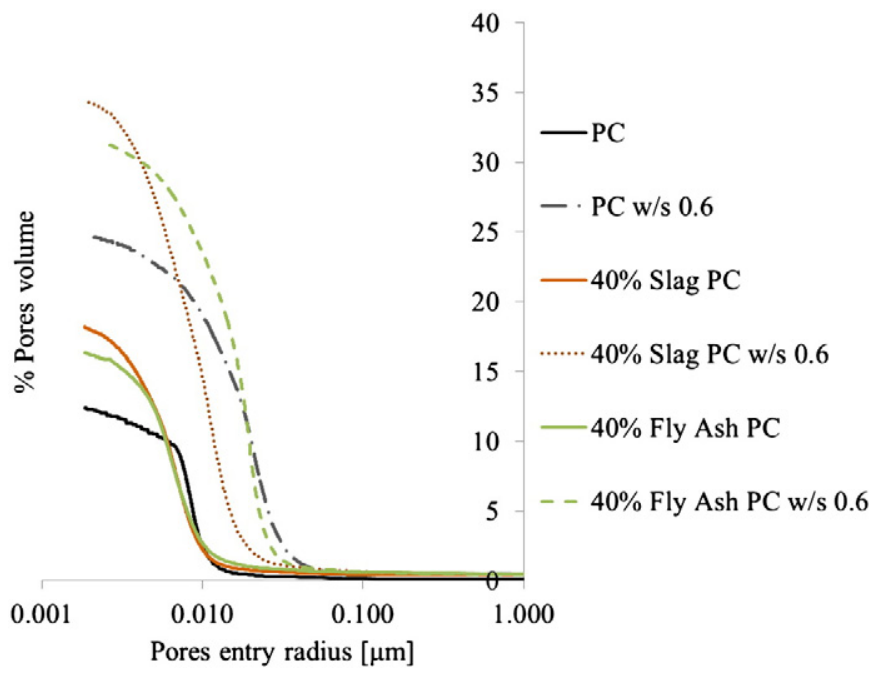

Fig. 19. Effect of increasing $\mathrm{w} / \mathrm{s}$ ratio on MIP curve at 28 days of PC, $40 \%$ slag and $40 \%$ fly ash systems at 60 days.

\section{Conclusions}

The present work brings new insights on the link between the reaction of different components in blended cements and the evolution of pore structure.

- Our results indicate that the clinker phase, slag and fly ash reactions are limited at later ages by the lack of water-filled capillary pores. It also means that for high replacement levels of SCMs (with constant water/solids ratio) lower degree of reaction are attained for slag and fly ash as previously reported [4,22,23].

- The reaction of slag and fly ash does not lead to such high increases in solid volume as does the reaction of clinker. For this reason the total porosity (when the replacement level is more than a few \%) in blended systems will always be higher, than in plain Portland cement pastes.

- It has been observed that fly ash and slag seem to have a different potential to fill the porosity. Slag is more reactive and contributes more strongly to porosity reduction even to the extent of suppressing the reaction of the clinker phases. This also means that there is more reduction in porosity in slag systems even when the water/solids ratio increases. It seems that fly ash needs to react to a much larger extent before significantly impacting the total pore volume, even if there is an earlier impact on the critical pore entry size.

- In all the systems studied, there seems to be a size for the critical pore entry which does not reduce further. It is interesting to note that, in a general sense, as the pore size decreases the solution needs to reach higher levels of supersaturation for precipitation to take place in it $[31,32]$. There could be other explanations for the stabilization of the pore size. For example, the increasing energy of the pore surfaces with higher curvature could also be important. However further analysis of this phenomenon lies beyond the scope of the present paper.

These observations give new insights on the way the reaction of slag and fly ash lead to modification in the pore structure of cementitious systems.

\section{Acknowledgments}

This work was financially supported by Nanocem, the industrialacademic partner in cement and concrete research (nanocem.org).

\section{References}

[1] B. Lothenbach, K. Scrivener, R.D. Hooton, Supplementary cementitious materials, Cem. Concr. Res. 41 (2011) 1244-1256.

[2] K. Luke, E. Lachowski, Internal composition of 20-year-old fly ash and slag-blended ordinary Portland cement pastes, J. Am. Ceram. Soc. 91 (2008) 4084-4092.

[3] J.I. Escalante-Garcia, J.H. Sharp, The chemical composition and microstructure of hydration products in blended cements, Cem. Concr. Compos. 26 (2004) 967-976.

[4] I.G.R.R. Taylor, Composition and microstructure of 20-year-old ordinary Portland cement-ground granulated blast-furnace slag blends containing 0 to $100 \%$ slag, Cem. Concr. Res. 40 (2010) 971-983.

[5] I. Richardson, G. Groves, Microstructure and microanalysis of hardened cement pastes involving ground granulated blast-furnace slag, J. Mater. Sci. 27 (1992) 6204-6212.

[6] R.L. Day, B.K. Marsh, Measurement of porosity in blended cement pastes, Cem. Concr. Res. 18 (1988) 63-73.

[7] B.K. Marsh, R.L. Day, D.G. Bonner, Pore structure characteristics affecting the permeability of cement paste containing fly ash, Cem. Concr. Res. 15 (1985) 1027-1038.

[8] R.F. Feldman, Pore Structure Formation during Hydration of Fly-ash and Slag Cement Blends, National Research Council Canada, Division of Building Research, 1982.

[9] C. Gallé, Effect of drying on cement-based materials pore structure as identified by mercury intrusion porosimetry: a comparative study between oven-, vacuum-, and freeze-drying, Cem. Concr. Res. 31 (2001) 1467-1477.

[10] S. Diamond, Mercury porosimetry: an inappropriate method for the measurement of pore size distributions in cement-based materials, Cem. Concr. Res. 30 (2000) $1517-1525$.

[11] J. Zhang, G.W. Scherer, Comparison of methods for arresting hydration of cement, Cem. Concr. Res. 41 (2011) 1024-1036.

[12] L. Konecny, S.J. Naqvi, The effect of different drying techniques on the pore size distribution of blended cement mortars, Cem. Concr. Res. 23 (1993) 1223-1228.

[13] N.C. Collier, J.H. Sharp, N.B. Milestone, J. Hill, I.H. Godfrey, The influence of water removal techniques on the composition and microstructure of hardened cement pastes, Cem. Concr. Res. 38 (2008) 737-744.

[14] R.M. Kowalczyk, A.M. Gajewicz, P.J. McDonald, The mechanism of waterisopropanol exchange in cement pastes evidenced by NMR relaxometry, RSC Adv. 4 (2014) 20709-20715.

[15] M. Moreira, Pore Structure in Blended Cement Pastes, Department of Civil Engineering, Technical University of Denmark, 2011. (PhD thesis).

[16] A. Valori, P.J. McDonald, K.L. Scrivener, The morphology of C-S-H: lessons from $1 \mathrm{H}$ nuclear magnetic resonance relaxometry, Cem. Concr. Res. 49 (2013) 65-81.

[17] D.H. Bager, E.J. Sellevold, Ice formation in hardened cement paste, Part II - drying and resaturation on room temperature cured pastes, Cem. Concr. Res. 16 (1986) 835-844.

[18] H.F. Taylor, Cement Chemistry, 2nd ed. Thomas Telford, 1997.

[19] C. Malami, V. Kaloidas, G. Batis, N. Kouloumbi, Carbonation and porosity of mortar specimens with pozzolanic and hydraulic cement admixtures, Cem. Concr. Res. 24 (1994) 1444-1454.

[20] A. Oner, S. Akyuz, An experimental study on optimum usage of GGBS for the compressive strength of concrete, Cem. Concr. Compos. 29 (2007) 505-514.

[21] A. Oner, S. Akyuz, R. Yildiz, An experimental study on strength development of concrete containing fly ash and optimum usage of fly ash in concrete, Cem. Concr. Res. 35 (2005) 1165-1171.

[22] L. Lam, Y.L. Wong, C.S. Poon, Degree of hydration and gel/space ratio of high-volume fly ash/cement systems, Cem. Concr. Res. 30 (2000) 747-756.

[23] M.B. Haha, K. De Weerdt, B. Lothenbach, Quantification of the degree of reaction of fly ash, Cem. Concr. Res. 40 (2010) 1620-1629.

[24] E. Berodier, K. Scrivener, Understanding the filler effect on the nucleation and growth of C-S-H, J. Am. Ceram. Soc. 97 (12) (2014) 3764-3773.

[25] P. Juilland, A. Kumar, E. Gallucci, R.J. Flatt, K.L. Scrivener, Effect of mixing on the early hydration of alite and OPC systems, Cem. Concr. Res. 42 (2012) 1175-1188.

[26] E. Gallucci, X. Zhang, K.L. Scrivener, Effect of temperature on the microstructure of calcium silicate hydrate (C-S-H), Cem. Concr. Res. 53 (2013) 185-195.

[27] V. Kocaba, E. Gallucci, K.L. Scrivener, Methods for determination of degree of reaction of slag in blended cement pastes, Cem. Concr. Res 42 (2012) 511-525.

[28] A.C.A. Muller, K.L. Scrivener, A.M. Gajewicz, P.J. McDonald, Densification of C-S-H measured by 1H NMR relaxometry, J. Phys. Chem. C 117 (2012) 403-412.

[29] Kocaba, Development and Evaluation of Methods to Follow Microstructural Development of Cementitious Systems including Slags, EPFL, 2009. (PhD thesis).

[30] K. Thoenen, Nagra/PSI chemical thermodynamic database $01 / 01$ for the GEMSelektor (V.2-PSI) geochemical modeling codeavailable at http://les.web.psi.ch/ Software/GEMS-PSI/doc/pdf/TM-44-03-04-web.pdf2003 (PSI Villigen).

[31] J. Bizzozero, C. Gosselin, K.L. Scrivener, Expansion mechanisms in calcium aluminate and sulfoaluminate systems with calcium sulfate, Cem. Concr. Res. 56 (2014) 190-202.

[32] M. Steiger, Crystal growth in porous materials-I: the crystallization pressure of large crystals, J. Cryst. Growth 282 (2005) 455-469. 